\title{
Bargaining in Legislatures: An Experimental Investigation of Open versus Closed Amendment Rules
}

\author{
Guillaume R. Frechette \\ Ohio State University
}

\author{
John H. Kagel \\ Ohio State University
}

January 31, 2000

\author{
Steven F. Lehrer \\ University of Pittsburgh
}

\begin{abstract}
We investigate the Baron and Ferejohn (1989) noncooperative game theoretic bargaining model of legislative equilibrium. Legislative outcomes are sensitive to formal rules specifying who may make proposals and how they will be voted on. With a random proposal recognition rule and a closed amendment rule (proposals are voted up or down with no room for amendments) the model predicts no delays in benefit allocation, that benefits will be allocated to a minimal winning coalition, and that benefits within the coalition will be strongly skewed in favor of the proposer. In contrast, with a random proposal recognition rule and an open amendment rule (proposals may be amended before they are voted on) the model predicts delays in benefit allocation, that benefits will be more evenly spread among winning coalition members, and that coalitions need not be restricted to a minimal majority. With experience we find strong qualitative support for the model's predictions: All proposals are passed without delay with the closed rule versus $81 \%$ of all proposals with the open rule. Minimal winning coalitions are effectively proposed in $67 \%$ of all cases with the closed rule versus $4 \%$ with the open rule, and benefits are more evenly distributed with open rule. Quantitative predictions of the model fail however: Most importantly, proposers consistently fail to allocate themselves anything close to what the theory predicts. Further, the probability of immediate acceptance is much higher than predicted in the open rule as proposers consistently expand the winning coalition beyond the model's prediction in attempts to limit amendments. The evolution of play over time is reported (outcomes under both treatments are much more similar early on then later). Tests show that subjects' votes in favor of a proposed allocation are significantly affected by their own share (in the expected direction) but that the distribution of shares across all voters has no significant effect.
\end{abstract}

Research support from the University of Pittsburgh is gratefully acknowledged. We have benefited from discussions with Hidehiko Ichimura, comments from seminar participants at Carnegie Mellon University and University of Pittsburgh and from programs of James Lesage. Kagel would like to thank the Economics Division and the DRMS Divisions of NSF for financial support. We are responsible for all errors. 


\section{Introduction}

Political economists have suggested that the two most important institutional variables that explain fiscal policies are the structure of the government and budgetary procedures, namely all the rules and regulations determining how budgets are prepared, approved and implemented. Non cooperative legislatures theory has focused on providing an answer to the following question: Do budget procedures matter for the determination of budget balance and its composition?

In their important contribution, Baron and Ferejohn (1989) present a sequential model of multilateral bar gaining with majority rule. They consider a bargaining model where $n$ risk neutral players are randomly selected to propose a division of a fixed sum of money where agreement requires the consent of a simple majority. They focus on the voting procedure (amendment rule) as it establishes who has influence on the final budget document, as well, as when and how. They distinguish between two types of amendment rules: closed rules and open rules.

There is a clear trade-off between these amendment rules. With a random proposal recognition rule and a closed amendment rule (proposals are voted up or down with no room for amendments) the model predicts no delays in benefit allocation, that benefits will be allocated to a minimal winning coalition, and that benefits within the coalition will be strongly skewed in favor of the proposer. In contrast, with a random proposal recognition rule and an open amendment rule (proposals may be amended before they are voted on) the model predicts delays in benefit allocation, that benefits will be more evenly spread among winning coalition members, and that coalitions need not be restricted to a minimal majority.

In this paper, we examine whether the equity and timing predictions of Baron and Ferejohn (1989) are realized in the laboratory. We ran several sessions where five subjects were asked to divide $\$ 25.00$ among themselves where only the amendment rule differed across sessions. We found that over time the different procedures led to different budget outcomes in terms of size and allocation of benefit. With experience we find strong qualitative support for the model's predictions: All proposals are passed without delay with the closed rule versus $81 \%$ of all proposals with the open rule. Minimal winning coalitions are effectively proposed in $67 \%$ of all cases with the closed rule versus $4 \%$ with the open rule, and benefits are more evenly distributed with open rule.

However, through an examination of the detailed pattern of play we observe that the quantitative predictions of the model fail. First, we found that the proposer never proposed himself a share as large as that predicted by theory. Although divisions in the closed rule became more uneven with the proposer seeking a larger share of the budget than the other members of the coalition. However, the proposer never proposed himself a share as large as that predicted by theory. Over the course of the session subjects learned the implications of majority rule voting with no possibility of an amendment by offering small amounts (if any at all) to non majority members.

Second, divisions in the open rule offered positive amounts of money to more subjects and were accepted more rapidly than predicted by theory. Subjects discovered that amendments are costly and proposed divisions which were more likely to be seconded. These distributions either took the form of offering an even split among the subjects or offering only one player less than one dollar.

Finally, in contrast to other experimental studies of bargaining games, we find that individuals elected to accept proposals based solely on their individual return (in the expected direction) and were not significantly affected by equity concerns. For example, in the first round of the open rule elections subjects would vote in favor of any proposal offering them more than $16 \%$ of the amount to be divided and voted against all proposals offering them less than $16 \%$; irrespective of fairness of the proposal being voted upon.

This paper is organized as follows. In the next section we introduce the model studied by Baron and Ferejohn (1989) and define the basic notation. In section III we discuss our experimental design. An analysis of the results of our experimental study are offered in section IV. We examine how these proposals change during the experimental sessions and to provide explanations for the patterns observed. We find that behavior converges to two different 
strategies in each treatment. Furthermore, we examine whether the underlying assumptions of our econometric models are indeed valid in our setting by utilizing a test statistic which compares the parametric estimator to a semi parametric estimator. We summarize our findings and compare our results with the existing literature on bargaining experiments in section $\mathrm{V}$.

\section{Theoretical Model and Predictions}

Baron and Ferejohn (1989) study a model reflecting the sequential nature of legislative action as structured by the rules employed to govern proposal making, amending and voting. The legislature consists of $n$ members each of whom represents a legislative district, a recognition rule that determines which member may make a proposal, an amendment rule, and a voting rule. The task of the legislature is to allocate a fixed quantity of divisible benefits among legislative districts according to majority rule. Each member of the legislature is assumed to have risk neutral preferences for benefits allocated only to their district, hence preferences are diametrically opposed. They restrict attention to stationary subgame perfect equilibria ${ }^{1}$.

At the beginning of each legislative session each member $i$ is chosen with probability of being recognized $p_{i}=$ $p_{j} \forall i, j \Rightarrow p=1 / n$. The recognized member makes a proposal $x^{i}$ specifying a distribution of shares, that is $x^{i}=\left(x_{1}^{i}, \ldots, x_{n}^{i}\right)$ such that $\sum_{j=1}^{n} x_{j}^{i} \leq 1$. This proposal is then the motion on the floor. Each member $i$ has the utility function $u^{i}\left(x^{j}, t\right)=\delta^{t} x_{i}^{j}$ where $\delta$ is the discount factor. ${ }^{2}$ They distinguish between two types of amendment rules (voting procedures): closed and open rules. Let's first consider the closed rule.

A closed rule is one in which the legislature must vote either for or against the proposal made by a member of the legislature without any opportunity of amendment. The legislature votes on the proposed distribution, essentially pegging it against the status quo, i.e. $x=(0, \ldots, 0)$. If the proposition is approved, the legislative adjourns. If the motion fails, the benefits are not allocated, and the legislature moves to the next round. In the next round the payoffs are discounted and the process starts over again. Under the closed rule, the predicted stationary equilibria split if there is the possibility of an infinite number of sessions is $\delta / n$ for $(n-1) / 2$ members, $[1-\delta(n-1) / 2 n]$ for the recognized member, and 0 for the remaining $(n-1) / 2$ members. ${ }^{3}$ Furthermore, the proposition should be accepted by a minimal majority and that in the first round.

In the open rule, amendments can be made to the motion on the floor. In the open rule, one amendment can be made and it is made by member $j$ which is recognized amongst the remaining $(n-1)$ members, that is with probability $\frac{p_{j}}{\sum_{k \neq i} p_{k}}$, which in our case turns out to be $\frac{p}{(n-1) p}=\frac{1}{n-1}$. This member can second the proposal, and then it is voted on as in the closed rule - if it passes, the legislature adjourns, and if it fails, they move to the next session - or he may propose an amendment to it. Note that the case where the amending process is finished and a vote is required may be referred to as 'move the previous question'. An amendment in this case is considered as an entirely new proposition. If an amendment is proposed, then the legislature votes between the motion on the floor and the proposed amendment. If the amendment is defeated, the original proposal remains on the floor and the next session begins, hence, payoffs are discounted. If they vote in favor of the amendment, then it becomes the motion on the floor, and payoffs are discounted as the legislature moves to the following session.

\footnotetext{
${ }^{1} \mathrm{~A}$ strategy profile is stationary subgame perfect if it is subgame perfect and if it does not depend on the current date and past history. These equilibria have the focal point property that the values of identical subgames are the same.

${ }^{2}$ We only consider the symmetric case even though their model is not limited to it. A symmetric recognition rule will not bias the results of the legislature in favor of any member as the member is selected at random to make a proposal. Having symmetric utility functions is still relatively general since $\delta$ can be interpreted as either or both the time discount factor or the probability of reelection, i.e. $\delta=\operatorname{Pr}$ (being re-elected) $\times$ time discount factor. Hence, as we have said, once it moves to the following session, the utilities are discounted and the process starts over again. They consider two possibilities, a finite and an infinite number of sessions, we will only deal with the infinite case.

${ }^{3}$ This division is for an odd number of members of legislature $(n)$.
} 


\begin{tabular}{|l|l|l|}
\hline Treatment & Closed Rule & Open Rule \\
\hline $\begin{array}{l}\text { Number of Subjects }(n) \\
\begin{array}{l}\text { Discount Factor }(\delta) \\
\text { Number of subjects who will receive a } \\
\text { positive payoff besides the proposer } \\
\text { Number of subjects who } \\
\text { receive zero payoff }\end{array}\end{array}$ & 0.8 & 0.8 \\
\hline Share to the proposer & 2 & 2 \\
\hline $\begin{array}{l}\text { Share to other subjects receiving } \\
\text { positive payoffs }\end{array}$ & 0.68 & 0.52 \\
\hline $\begin{array}{l}\text { Probability of proposal being } \\
\text { approved in the 1st round }\end{array}$ & 1 & 0.24 \\
\hline
\end{tabular}

Table 1: Theoretical Predictions: Stationary Equilibria

The predictions of the open rule take a slightly different form. First, the number of people getting a strictly positive money offer beside the recognized member is not necessarily $(n-1) / 2$. This number, denoted $m(\delta, n)$, is determined by the formula

$$
m(\delta, n) \in \underset{m}{\arg \max } V^{m}(\widehat{y})
$$

where

$$
\begin{aligned}
V_{1}^{m}(\widehat{y}) & =\frac{m}{(n-1)\left(\left(1+\delta\left(\frac{m^{2}}{n-1}\right)-\delta^{2}\left(1-\frac{m}{n-1}\right)\left[\frac{1}{n-1}+\left(1-\frac{(m+1)}{n-1}\right) \gamma\right]\right)\right)} \\
\gamma & =\frac{\delta}{B}\left[\frac{m}{n-1}+\delta\left(1-\frac{m}{n-1}\right) \frac{n-m-2}{m(n-1)}\right] \\
B & =1-\frac{2 m-n+2}{m}\left(1-\frac{m}{n-1}\right) \delta-\frac{n-m-2}{m}\left(1-\frac{m+1}{n-1}\right)\left(1-\frac{m}{n-1}\right) \delta^{2}
\end{aligned}
$$

Another difference in predictions is that the proposition is not necessarily approved in the first round. Finally, the recognized member has less power than in the closed rule case and thus her share decreases. Her share is given by $\widehat{y}^{a}=1-m(\delta, n) \delta V_{1}^{m}\left(\widehat{y}^{1}\right)$.

For example, with a sample size of five and a discount factor of 0.8 (our specific $n$ and $\delta$ ), under the closed rule the recognized member should receive 0.68 of the total amount to be divided, 2 other members should each receive 0.16 of the amount to be divided and the remaining 2 members would not receive any funds. The predicted stationary equilibria split in the open rule if there is the possibility of an infinite number of sessions is 0.52 for the recognized member, 0.24 for $(n-1) / 2$ members, and 0 for the remaining $(n-1) / 2$ members. Thus, as in the closed rule two subjects would not receive any funds but now the probability that the election ends in a single round is cut in half. It should be noted that the fact that a fifty plus one percent majority is predicted for the open rule is a special case, for many other $n$ and $\delta$, the predicted coalition is much bigger. We summarize the theoretical predictions (for our specific $n$ and $\delta$ ) in table 1 .

We can summarize the predictions from theory as follows. First, an open rule creates delays in the approval of a proposal. Second, a closed rule leads to the adoption of majoritarian allocation rules. That is, the benefits are allocated to 50 percent plus one fraction of the legislature. An open rule may lead to a distribution of benefits in 
which more than the minimum majority of legislators receive positive net benefits. Third, with an open rule the distribution of benefits within the winning majority are more egalitarian than with a closed rule. ${ }^{4}$ In the following section we discuss the way we test the predictions of these theories in the laboratory setting.

\section{Experimental Design}

Five subjects were recruited for each experiment consisting of a series of fifteen meetings (called elections) of the legislature. Only the amendment rule differed between sessions but not within any session. Recall, under the closed rule the legislature must vote either for or against the proposal made by a member of the legislature without any opportunity of amendment. If the proposal is accepted the game is over and the budget is approved; if it is rejected a new member of the legislature can make another proposal which is again voted up or down. Under the open rule the proposal can be amended from the floor. That is, the first member selected makes a proposal. Another member is then selected and she can either ask for a vote on the proposal in its current form or propose an amendment. In the second case, the amendment is balloted against the proposal. The winner becomes the new proposal on the floor and a new member is selected, and so forth. A total of four sessions were run for each treatment. ${ }^{5}$

At the start of each election in either treatment the five subjects became members of the legislature and were randomly assigned a subject number by the experimenter. This number was known only to the individual subject and changed across but not within elections. Each subject would then fill out a proposal form and allocate $\$ 25.00$ among the members of the legislature by their subject numbers. Once the proposal forms were completed and collected by the experimenter, a roll of a five sided die was used to determine which proposal would take the floor; based on subject number. This proposal along with the subject number (but not the actual identity) was then posted on a blackboard in both treatments.

Subsequently, in a closed rule session each subject would next complete a voting form to mark down whether they accepted or rejected the division currently being proposed. The voting forms were then collected and tabulated by the experimenter. If a simple majority accepted the proposal then the payoff was implemented and the election ended. If the proposal was rejected by a simple majority then each subject would have to propose a new division of the remaining funds in the next round of the election. A discount rate of 0.8 was used in all sessions. The results of the election were posted on the blackboard underneath the proposal. The blackboard contained information only on the last four proposals which were voted upon.

In an open rule session each subject would subsequently complete a form where they would determine whether they wished to second or amend the division currently proposed. The experimenter collected the forms and a roll of a four sided die determines which subject would have the power to second or amend. If this subject seconded the proposal it would pass to an election as in the closed rule. If this subject wished to amend the proposal, she was required to propose an alternative distribution of the funds. In this case, a runoff election was held between the original proposal and the amendment. The amendment along with the subject number (but not the actual identity) of the amender would be posted on the blackboard underneath the original proposal. A runoff election form would be completed by the subjects, collected, and tabulated by the experimenter. The proposal which was selected by a simple majority would then be the standing proposal in the next round of the election. However, all amounts would be discounted by 0.8 as there is a cost to having this extra election. The election continues in this manner until a proposal is both seconded and approved by a simple majority.

\footnotetext{
${ }^{4}$ Another implication which we will not study is that a closed rule has been shown by Baron (1991) to lead to the adoption of more inefficient budgets.

${ }^{5}$ It should be noted that we originally designed this experiment to have ten elections in each session. After completing one session of each treatment and eyeballing the data we were uncertain whether behavior within the sessions had converged to a rule of thumb strategy. It was clear that the strategies were evolving in certain directions and we felt that increasing the number of elections to fifteen, we would see if there indeed was convergence.
} 
Subjects were recruited through announcements in undergraduate classes and advertisements in student newspapers at the University of Pittsburgh and Carnegie Mellon University. The advertisements in student newspapers resulted in recruiting a broad cross section of graduate and undergraduate students from both campuses. Subjects were paid based on the results of four of these meetings which were randomly chosen (by four rolls of a fifteen sided die) at the conclusion of the experiment. Each subject also received a participation fee of $\$ 5$.

An additional subject was recruited for each session to roll the dice during the session. We felt having a subject roll the dice as opposed to the experimenter would ensure that the remaining subjects realized that outcomes were determined at random. This subject was chosen at random at the beginning of each session by a roll of a six sided die by the experimenter. This subject received a fixed fee of fifteen dollars for rolling the dice during the experiment.

Under both treatments a practice election was held to familiarize the subjects with the procedures and accounting rules. In the case of the open rule we covered both the case of an amendment being made and not being made to the motion on the floor. A copy of the instructions used in the closed rule and open rule sessions are provided in Appendix A and B respectively. In the following section we present the results from these experiments.

\section{Results}

Table 2 reports several summary statistics from all of the sessions run for both treatments using every proposal ${ }^{6}$. As discussed in the preceding section, each subject proposes the division of the funds across the five subjects by subject number using the proposal form. The individual's subject number is clearly marked in the top right hand corner of each proposal form. Results are separately reported for all elections of the play, for the first five and for the last five elections to illustrate changes in behavior.

There are several interesting discrepancies with the theory that immediately appear. First, the probability of a proposal being accepted in the first round under the open rule is higher than predicted. A t-test of the null hypothesis that the probability the election will end at round one is equal to the theoretical prediction of 0.5 is rejected ${ }^{7}$. As shown in figure 1, as the session progresses, a higher percentage of elections end within one round in the open rule. ${ }^{8}$

Second, in each open rule session subjects quickly learn that amendments are costly. Thus, subjects increased the share given to the two outsiders during the session which led to the higher acceptance rate of proposals in the first round. Furthermore in the last five elections of the open rule sessions, not a single subject offered two zeros. This is in sharp contrast with the theory that predicts that in both the closed and open rule sessions, subjects should offer strictly positive amounts of money to only two other players. The two remaining players should not be offered anything in either treatment. Subjects are clearly increasing their offers to these members in order to reduce the likelihood of an amendment being proposed. Notice that the proportion of subjects who are seconding the motion on the floor increases from $65.5 \%$ in the first five elections to $80.9 \%$ in the last five elections. Finally, in later elections not a single election lasted more than two rounds whereas early on there were lengthy battles in each election.

Third, the proposers do not take as much as theory predicts in neither the open nor the closed rule. Theory predicts that the proposer will offer herself $\$ 17.00$ and $\$ 13.00$ in the closed rule and open rule respectively. A t-test that the amounts offered to oneself is equal to the theoretical prediction in both treatments is clearly rejected. In the open rule subjects seem to offer themselves a constant fraction while in the closed rule the share increases during the session. However, in the last five elections the share offered to oneself is only slightly more than $50 \%$ of the

\footnotetext{
${ }^{6}$ We are not examining solely the motion on the floor unless otherwise indicated.

${ }^{7} P>|t|=0.0011$

${ }^{8}$ In the closed rule there were only two elections which entered multiple rounds. The original motions on the floor were $(7,5,4,5,4)$ and $(6,3,7,3,6)$ which led to votes (accept, reject, reject, accept, reject) and (reject, reject, accept, reject, accept) respectively. In both cases, the subjects who made the voting errors offered themselves one dollar less in the subsequent round of the election than what they would have received had they accepted the original motion on the floor. We think a strong argument can be made that these initial rejections were due to errors made by subjects especially since they occured early in the sessions.
} 


\begin{tabular}{|c|c|c|c|c|c|c|}
\hline & \multicolumn{2}{|c|}{ Full Sample (All Elections) } & \multicolumn{2}{|c|}{ First Five Elections (1-5) } & \multicolumn{2}{|c|}{ Last Five Elections (11-15) } \\
\hline & Closed Rule & Open Rule & Closed Rule & Open Rule & Closed Rule & Open Rule \\
\hline $\begin{array}{l}\text { Probability of Proposal } \\
\text { Being Approved in Round } 1\end{array}$ & 0.964 & 0.745 & 0.900 & 0.650 & 1.000 & 0.867 \\
\hline $\begin{array}{l}\text { Probability of Proposal } \\
\text { Being Approved in Round } 2\end{array}$ & 1.000 & 0.571 & 1.000 & 0.429 & $\mathrm{NA}$ & 1.000 \\
\hline $\begin{array}{l}\text { Probability of Proposal } \\
\text { Being Approved in Round } 3\end{array}$ & NA & 0.500 & NA & 0.250 & NA & NA \\
\hline $\begin{array}{l}\text { Amount to the } \\
\text { Proposer in Round } 1\end{array}$ & $\begin{array}{l}8.431 \\
(2.913)\end{array}$ & $\begin{array}{l}6.487 \\
(1.128)\end{array}$ & $\begin{array}{l}7.213 \\
(3.454)\end{array}$ & $\begin{array}{l}6.639 \\
(1.433)\end{array}$ & $\begin{array}{l}9.227 \\
(2.524)\end{array}$ & $\begin{array}{l}6.362 \\
(0.808)\end{array}$ \\
\hline $\begin{array}{l}\text { Probability of Two Subjects } \\
\text { Receiving Zero Payoffs in Round } 1\end{array}$ & 0.262 & 0.018 & 0.120 & 0.030 & 0.333 & 0.000 \\
\hline $\begin{array}{l}\text { Average Sum of the Two Lowest } \\
\text { Amounts Proposed in Round } 1\end{array}$ & $\begin{array}{l}4.458 \\
(3.884)\end{array}$ & $\begin{array}{l}6.998 \\
(2.695)\end{array}$ & $\begin{array}{l}6.145 \\
(3.461)\end{array}$ & $\begin{array}{l}6.843 \\
(3.191)\end{array}$ & $\begin{array}{l}3.293 \\
(3.972)\end{array}$ & $\begin{array}{l}7.059 \\
(2.068)\end{array}$ \\
\hline $\begin{array}{l}\text { Probability of the Motion on the } \\
\text { Floor Being Seconded in Round } 1 *\end{array}$ & NA & 73.27 & NA & 65.49 & NA & 80.88 \\
\hline
\end{tabular}

Numbers in parenthesis are standard deviations.

* Remember that the original proposer cannot amend his own proposal. In the experiment, the proposer completes a form to preserve anonymity but it would not be selected and is therefore not included.

Table 2: Summary Statistics
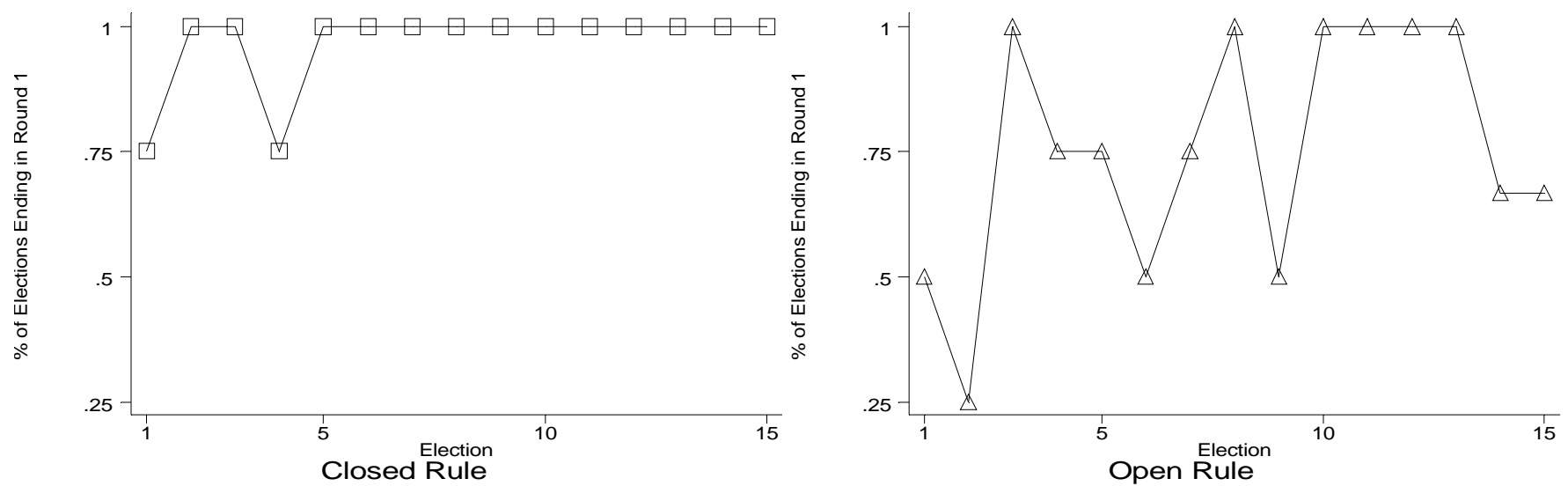

Figure 1: Probability of Acceptance in Round 1 


\begin{tabular}{|l|l|l|l|l|l|l|}
\hline \multirow{2}{*}{$\begin{array}{l}\text { Sum of the Two Lowest Amounts } \\
\text { Proposed in Round 1 }(o)\end{array}$} & \multicolumn{2}{|l|}{ Full Sample (All Elections) } & \multicolumn{2}{l|}{ First Five Elections (1-5) } & \multicolumn{2}{l|}{ Last Five Elections (11-15) } \\
\cline { 2 - 7 } & Closed Rule & Open Rule & Closed Rule & Open Rule & Closed Rule & Open Rule \\
\hline$o=0.00$ & $26.18 \%$ & $1.82 \%$ & $12.00 \%$ & $3.00 \%$ & $33.33 \%$ & $0.00 \%$ \\
\hline $0.00<0 \leq 2.00$ & $15.27 \%$ & $7.27 \%$ & $9.00 \%$ & $12.00 \%$ & $32.00 \%$ & $4.00 \%$ \\
\hline $2.00<0 \leq 4.00$ & $9.82 \%$ & $5.82 \%$ & $9.00 \%$ & $8.00 \%$ & $\mathbf{0 . 0 0 \%}$ & $4.00 \%$ \\
\hline $4.00<0 \leq 6.00$ & $10.18 \%$ & $21.09 \%$ & $15.00 \%$ & $14.00 \%$ & $5.33 \%$ & $22.67 \%$ \\
\hline $6.00<0 \leq 8.00$ & $19.64 \%$ & $26.55 \%$ & $27.00 \%$ & $22.00 \%$ & $13.33 \%$ & $40.00 \%$ \\
\hline $8.00<0 \leq 10.00$ & $0.73 \%$ & $19.64 \%$ & $1.00 \%$ & $14.00 \%$ & $\mathbf{0 . 0 0 \%}$ & $20.00 \%$ \\
\hline$o=10.00$ & $18.18 \%$ & $17.82 \%$ & $27.00 \%$ & $27.00 \%$ & $16.00 \%$ & $9.33 \%$ \\
\hline
\end{tabular}

Table 3: Descriptions of Two Lowest Amounts Offered in Individual Proposals

theoretical prediction. In fact only three subjects offered themselves more than $\$ 10.00$ in the first round of the last five elections of the closed rule. ${ }^{9}$

Fourth, convergence of behavior across subjects over time differs across treatments. A priori, we were expecting standard errors to decrease over time. That is we believed the behavior of subjects would become increasingly similar during the experiment. This is indeed the case in the open rule as one can see by comparing the standard errors of the amount one offers themselves and the share offered to the two outsiders between the first five and last five elections. However, the standard deviations increase over time for the share offered to the two outsiders in the closed rule.

There seems to be a great deal of variation in the strategies that subjects employ to deal with these two outsiders. We present the percentage of proposals that offer these subjects funds in two dollar intervals in table 3 . Kernel density estimates ${ }^{10}$ of these offers are shown in figure 2 and point out that the offers are bunched at certain values and not spread evenly in the intervals listed in table 3 . We observe there is a clear shift of the density between the first five and last five elections in the closed rule. As well, in the last five elections of the open rule we see few proposals offering less than four dollars to the two outsiders.

Behavior after the tenth election can be characterized fairly simply as shown in table 4 . In the closed rule, roughly one third of the subjects were proposing each subject at least four dollars (20\% of the pie in the first round). This strategy is defined to be an even split (ES). The remaining two thirds were playing an extended version of the double zero (DZ) strategy in which the sum of two lowest offers is less than or equal to $\$ 2.00$. For example, subjects would offer a split: $9,7.50,7.50,0,1$. Clearly, the one dollar in this example is similar to a zero since they know it will be rejected. A breakdown of offers following the DZ strategy indicate that $51 \%$ of them contain two zeros. In fact, $96 \%$ of the offers classified as DZ offer at least one zero and an amount less than or equal to one dollar for the other outsider. In the open rule only $4 \%$ of the offers satisfy the double zero requirement as defined above. However, there is also a natural division into two major strategies for the open rule; the single zero (SZ) strategy and the ES. We define the SZ strategy to be a proposal that offers one subject one dollar or less, and the ES is defined as before. Of the subjects playing the SZ strategy, $61 \%$ offered nothing to one player.

It is clear that offers are evolving in opposite directions between the two treatments. We illustrate how the treatments differ in terms of allocation to oneself, allocation to non majority members and fairness of the offers across all subjects in the first round of each election over the course of the session in figure 3 . To analyze fairness in this experiment we employ a fairness index (henceforth referred to as FI) which measures deviations from a uniform

\footnotetext{
${ }^{9}$ One subject offered herself $\$ 15.00$ in each of the last five elections while the other two subjects offered themselves $\$ 13.00$ and $\$ 15.00$ but only in the last election.

${ }^{10}$ An Epanechnikov kernel was used for these estimates. A detailed description of this method is provided in the discussion of the trimming function in Appendix C.
} 

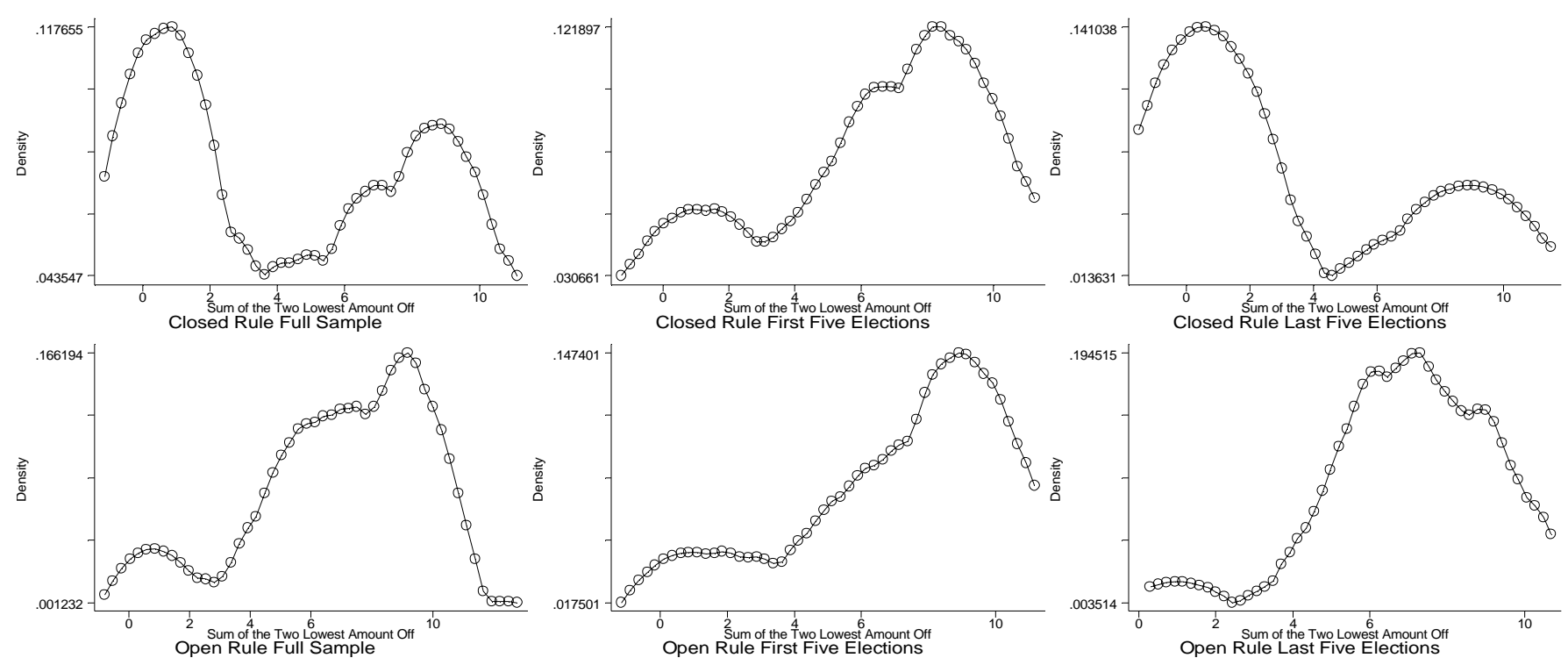

Figure 2: Kernel Density Estimates

\begin{tabular}{|l|l|l|l|}
\hline \multicolumn{2}{|l|}{ Closed Rule } & \multicolumn{2}{l|}{ Open Rule } \\
\hline Double Zero Strategy & $65.33 \%$ & Single Zero Strategy & $48 \%$ \\
\hline Even Split & $29.33 \%$ & Even Split & $40 \%$ \\
\hline All other strategies & $5.33 \%$ & All other strategies & $12 \%$ \\
\hline
\end{tabular}

Table 4: Categories of Behavior 
distribution of the money and is normalized to lie between 0 and 1 by dividing this value with that of the most uneven distribution where one person takes everything. Specifically FI $=\sum_{i=1}^{n}\left(a_{i}-\frac{T}{n}\right)^{2} /\left\{\left(T-\frac{T}{n}\right)^{2}+(n-1)\left(\frac{T}{n}\right)^{2}\right\}$, where $a_{i}$ is the amount allocated to player $i, T$ is the total amount of money, and $n$ is the number of players.

Notice both the open and closed rules start with virtually the same take for the proposer. ${ }^{11}$ Although there is substantial growth in the take in the closed rule there is an immediate decline in the open rule and behavior quickly converges. We perform a Mann-Whitney U test (or Wilcoxon rank-sum test) on the average value over the last five periods of the take per subject which tests the hypothesis that two independent samples are from populations with the same distribution. The null hypothesis that the open and closed rule have the same distribution of the take is rejected $(\operatorname{Prob}>|z|=0.0006)$.

Similarly in the graph showing the average sum to the two outsiders the two treatments starts off at a similar point but they quickly bifurcate. A Mann-Whitney U test on the average value over the last five periods of this variable per subjects rejects the null hypothesis that these variables take the same values for these two groups (Prob $>|z|=0.0113)$. A Mann Whitney test also rejects the null hypothesis that the FI variable take the same values for thee two groups $(\operatorname{Prob}>|z|=0.0051)$.

Two clear patterns seem to emerge from figure 3. First, the open and the closed rule generate different level of equity in the distribution of payoffs. Second, the behavior seems to change significantly as the number of election increases. It is our belief that the relationship between the election and the level of equity of the offers in part reflects learning. The type of learning we have in mind is that agents are slowly figuring out the structure of the game. For instance, even though the instructions clearly mention that a simply majority is all that is required to approve a proposal, it may take subjects time to understand the strategic implications of that fact. Notice in figure 4 that the percentage of subjects who offer two zeroes in the closed rule increases over time.

We also plot the share that the proposer offers herself when she follow the DZ strategy in figure 4 . Notice the increase in the share that the proposer offers herself in the closed rule can be explained by the increase in the proportion of subjects following the double zeros strategy. Although switching to play the DZ strategy would allow subjects to increase their take, the amount taken is fairly constant across subjects following the DZ strategy after the fifth election. The graph of the average offer to herself for all subjects moves proportionately with the graph of offers to herself conditional on playing the double zero strategy following the seventh election.

The increase in the proportion of subjects following the DZ strategy and the evolution of a session are highly dependent on which offers take the floor. Some subjects do not realize by themselves that they can offer two zeroes, but once such an offer takes the floor, it is more likely that they will do so. For example in the fourth closed rule session, an offer satisfying the DZ requirements did not appear on the floor until the tenth election. Prior to this election only one subject was making proposals consistent with the DZ strategy. However, by the twelfth election four subjects were playing the DZ strategy.

Although the results seems surprising as the observed behavior departs from the theory the results do strengthen the theoretical prediction of a more equitable distribution under the open rule. Although we have presented several explanations for the observed behavior one may wonder if risk aversion is a valid explanation for the outcomes under the closed rule. Recall, the theoretical model assumes risk neutral subjects. Risk aversion is only a valid explanation if the proposer believes herself to be more risk averse than all the other members of the legislature.

As discussed above, subjects quickly learned that amendments are costly in the open rule sessions and made proposals which were more likely to be seconded. Since subjects increasingly followed the SZ strategy it is not surprising that as shown in table 5 the amount that subjects would turn down in order to create an amendment fell by nearly one dollar in round one and one percentage point in share between the first five and last five elections.

When constructing amendments subjects understood they should offer the two worst off subjects larger (improved) shares. This occurred in all but one instance. However, subjects did not immediately understand how to create an

\footnotetext{
${ }^{11}$ This is averaged across subjects in the first round.
} 

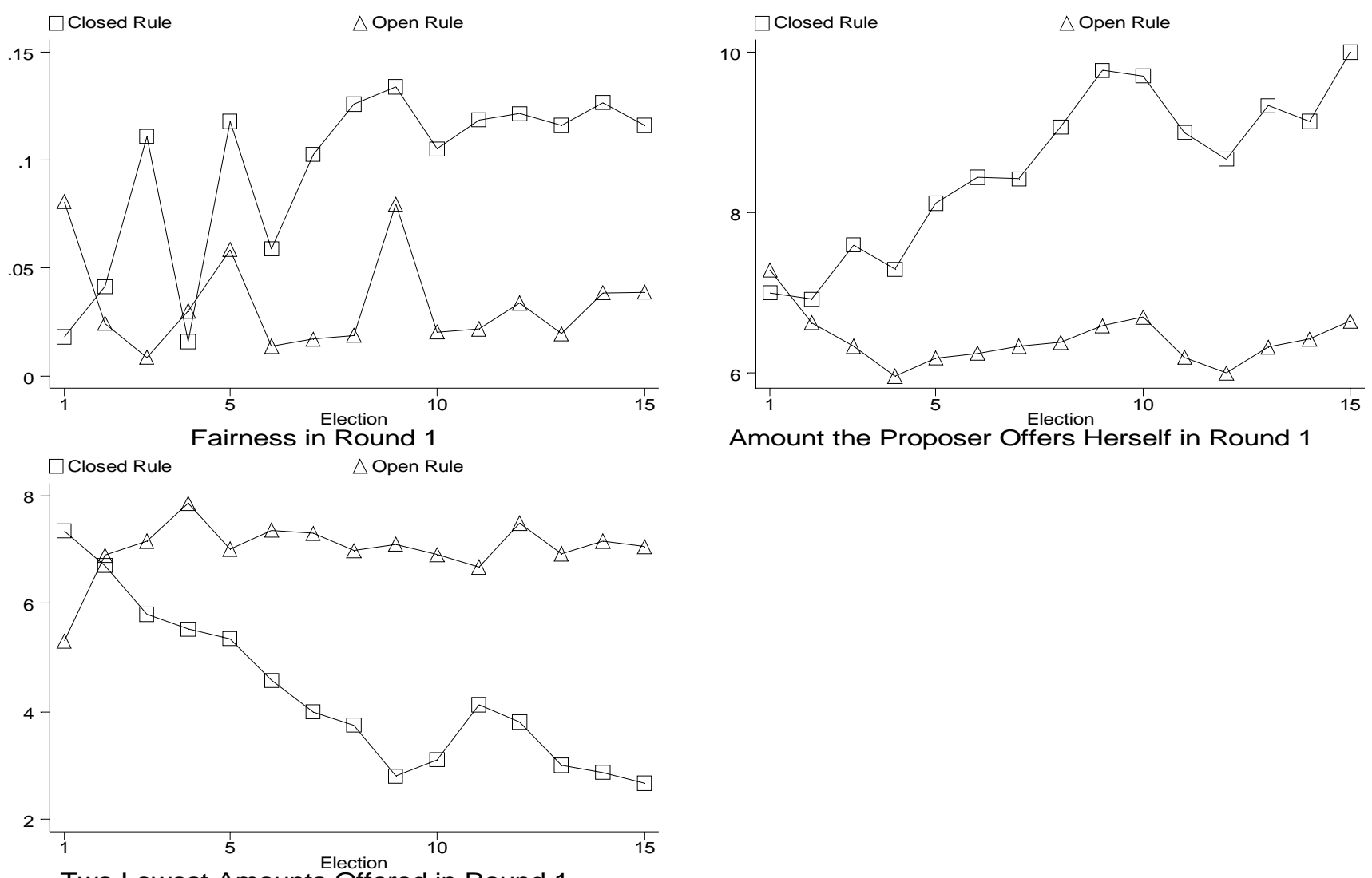

Amount the Proposer Offers Herself in Round 1

Two Lowest Amounts Offered in Round 1

Figure 3: Evolution of Various Aspects of the Offers Over Time

\begin{tabular}{|l|l|c|c|}
\hline & Full Sample (All Elections) & First Five Elections (1-5) & Last Five Elections (11-15) \\
\hline $\begin{array}{l}\text { Percentage of Amendments } \\
\text { Offering at Least Two Subjects } \\
\text { the Same or Greater Share }\end{array}$ & 54.87 & 53.33 & 84.21 \\
\hline $\begin{array}{l}\text { Percentage of Times the Two Worst } \\
\text { Off Receive an Improved Share }\end{array}$ & 98.21 & 97.7 & 100 \\
\hline $\begin{array}{l}\text { Average Share Refused When } \\
\text { Proposing an Amendment }\end{array}$ & $\mathbf{0 . 0 7 3}$ & $\mathbf{0 . 0 7 5}$ & $\mathbf{0 . 0 6 5}$ \\
\hline $\begin{array}{l}\text { Average Amount Refused by } \\
\text { Proposing an Amendment in Round 1 }\end{array}$ & $\begin{array}{l}\$ 2.21 \\
(1.93)\end{array}$ & $\$ 2.075)$ & $(0.085)$ \\
\hline
\end{tabular}

Table 5: Summary Statistics on Amendments Proposed 

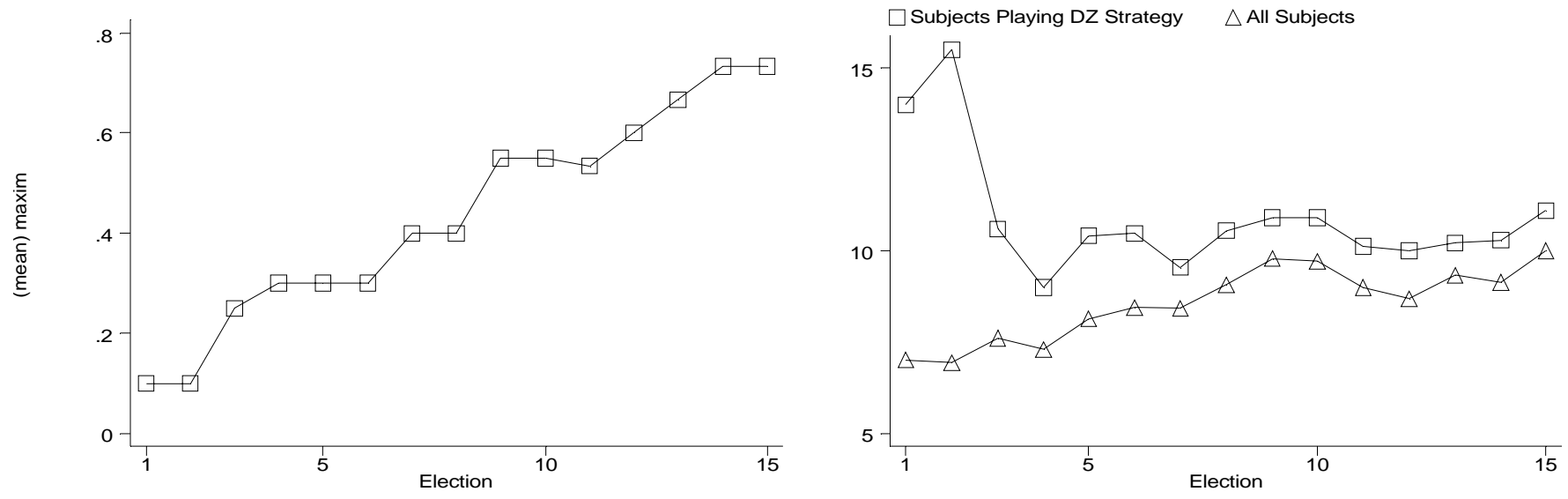

Figure 4: Percentage of Subjects Offering Two Zeroes and Their Offers to Themselves in the Closed Rule

amendment which would be successful in the runoff election. Notice that slightly less than $55 \%$ of the amendments offered improved shares to at least two other subjects besides the amender. Over the course of the sessions subjects learned how to propose a successful amendment as 30\% more amendments offered improved shares to at least two other subjects. Only two subjects in the last five elections suggested amendments that theory predicts would not be approved.

It is clear that behavior differs across treatments in terms of the distribution of benefits. In terms of the voting behavior of the individual subjects there also exists several differences across the treatments. In the following table we present the number of people who vote for and against a given proposal based on the share of the funds they would receive if it were accepted by a simple majority. We exclude voting data where the voter is the proposer since it is obvious that in this case she will vote in favor of what she allocated to herself. Notice in table ??, that there are several instances in the open rule sessions where subjects voted in favor of receiving less than $15 \%$ of the funds. These circumstances occurred only in the last round of several multiple round elections. Also notice in the closed rule that there were six instances that subjects rejected receiving between 20 to 25 percent of the funds available but as mentioned earlier these can mostly be treated as mistakes ${ }^{12}$.

In order to examine individual voting decisions we constructed the following equation

$$
\text { vote }_{i t}=\beta_{0}+\beta_{1 S_{i t}}+\beta_{2} F I_{i t}+\beta_{3} T_{i t}+u_{i t} ; \quad \mu_{i t} \sim N\left(0, \sigma^{2}\right)
$$

where vote is a limited dependent variable and our explanatory variables include the share the voter is receiving (s), the fairness of the proposal as measured by the fairness index and time dummies (for every three elections) to capture the adjustment process in a flexible manner. We estimate this model using the probit and random effects probit $^{13}$, maximum likelihood technique which rely on the assumption that $\mu_{i t} \sim N\left(0, \sigma^{2}\right)$. However there is no

\footnotetext{
${ }^{12}$ In fact four of the six votes against were done when an even split was proposed. The same subjects did accept the same share in situations where the DZ strategy was followed. The other two cases are the mistakes discussed earlier which led to a second round.

${ }^{13}$ This estimator takes advantages of our longitudal data and decomposes the error term into an individual component $\alpha_{i}$ and random disturbance $\nu_{i t}$ such that: $u_{i t}=\alpha_{i}+\nu_{i t}$. It relaxes the assumption of independence across observations and employs a GLS procedure which yields more efficient estimates than the other methods.
} 


\begin{tabular}{|c|c|c|c|c|}
\hline $\begin{array}{l}\text { Share Offered } \\
\text { (Share in dollars) }\end{array}$ & $\begin{array}{l}\text { Closed Rule } \\
\text { Vote in Favor }\end{array}$ & $\begin{array}{l}\text { Closed Rule } \\
\text { Vote Against }\end{array}$ & $\begin{array}{l}\text { Open Rule } \\
\text { Vote in Favor }\end{array}$ & $\begin{array}{l}\text { Open Rule } \\
\text { Vote Against }\end{array}$ \\
\hline $0 \leq s \leq 5 \%$ & 0 & 53 & 3 & 20 \\
\hline $5<s \leq 10 \%$ & 0 & 5 & 0 & 5 \\
\hline $10<s \leq 15 \%$ & 0 & 9 & 2 & 3 \\
\hline $15<s \leq 20 \%$ & 25 & 11 & 43 & 4 \\
\hline $20<s \leq 25 \%$ & 69 & 6 & 113 & 0 \\
\hline $25<s \leq 30 \%$ & 30 & 0 & 18 & 0 \\
\hline $30<s \leq 35 \%$ & 13 & 0 & 8 & 0 \\
\hline$s>35 \%$ & 7 & 0 & 1 & 0 \\
\hline \multicolumn{5}{|c|}{ Round One Only } \\
\hline $\begin{array}{c}0 \leq s \leq 5 \% \\
(0-\$ 1.25)\end{array}$ & 0 & 52 & 0 & 10 \\
\hline $\begin{array}{c}5<s \leq 10 \% \\
(\$ 1.26-\$ 2.50)\end{array}$ & 0 & 5 & 0 & 4 \\
\hline $\begin{array}{l}10<s \leq 15 \% \\
(\$ 2.51-\$ 3.75)\end{array}$ & 0 & 9 & 0 & 3 \\
\hline $\begin{array}{l}15<s \leq 20 \% \\
(\$ 3.46-\$ 5.00)\end{array}$ & 25 & 11 & 42 & 4 \\
\hline $\begin{array}{c}20<s \leq 25 \% \\
(\$ 5.01-\$ 6.25)\end{array}$ & 66 & 5 & 88 & 0 \\
\hline $\begin{array}{l}25<s \leq 30 \% \\
(\$ 6.26-\$ 7.50)\end{array}$ & 27 & 0 & 13 & 0 \\
\hline $\begin{array}{l}30<s \leq 35 \% \\
(\$ 7.51-\$ 8.75) \\
\end{array}$ & 13 & 0 & 0 & 0 \\
\hline $\begin{array}{c}s>35 \% \\
(>\$ 8.75)\end{array}$ & 7 & 0 & 0 & 0 \\
\hline
\end{tabular}

Table 6: Accepted and Rejected Offers 


\begin{tabular}{|c|c|c|c|c|c|c|}
\hline & \multicolumn{3}{|c|}{ Closed Rule } & \multicolumn{3}{|c|}{ Open Rule } \\
\hline $\begin{array}{l}\text { Independent } \\
\text { Variable }\end{array}$ & Probit & $\begin{array}{l}\text { Random } \\
\text { Effects Probit }\end{array}$ & SLS* & Probit & $\begin{array}{l}\text { Random } \\
\text { Effects Probit }\end{array}$ & SLS \\
\hline Share & $\begin{array}{l}28.933 \\
(5.309) \\
\end{array}$ & $\begin{array}{l}65.727 \\
(16.931) \\
\end{array}$ & 0.880 & $\begin{array}{l}19.701 \\
(3.150)\end{array}$ & $\begin{array}{l}23.505 \\
(6.303) \\
\end{array}$ & 0.998 \\
\hline Fairness Index & $\begin{array}{l}4.428 \\
(5.181) \\
\end{array}$ & $\begin{array}{l}-2.727 \\
(9.931)\end{array}$ & 0.455 & $\begin{array}{l}-3.066 \\
(5.251) \\
\end{array}$ & $\begin{array}{l}-2.527 \\
(5.977) \\
\end{array}$ & 0.000 \\
\hline Constant & $\begin{array}{l}-4.531 \\
(1.017) \\
\end{array}$ & $\begin{array}{l}-10.381 \\
(2.648) \\
\end{array}$ & -0.135 & $\begin{array}{l}-1.768 \\
(0.589) \\
\end{array}$ & $\begin{array}{l}-2.147 \\
(0.867) \\
\end{array}$ & -0.050 \\
\hline Sample Size** & $\mathrm{N}=228$ & $\mathrm{~N}=228$ & $\mathrm{~N}=181$ & $\mathrm{~N}=220$ & $\mathrm{~N}=220$ & $\mathrm{~N}=190$ \\
\hline Log Likelihood & -46.960 & -31.488 & & -28.013 & -27.557 & \\
\hline \multicolumn{7}{|c|}{ Share Coefficient Normalized to one } \\
\hline Fairness Index & 0.153 & -0.041 & 0.517 & -0.156 & -0.108 & 0.000 \\
\hline Constant & -0.157 & -0.158 & -0.153 & -0.090 & -0.091 & -0.050 \\
\hline
\end{tabular}

Numbers in parenthesis are standard deviations.

* Since the SLS is performed over a trimmed sample, we have computed the probits and random effects probits over that sample, neither produced strickingly differet results.

${ }^{*}{ }^{*}$ The sample sizes differ between the treatments since there were a different number of elections. Recall, in the open rule an election will be held in a round only if the motion on the floor is seconded, otherwise a runoff election was held. As discussed in the appendix the SLS estimates employ a trimming function which result in a smaller sample size.

Table 7: Econometric Estimates of the Voting Equation

a priori reason to believe that the distributional assumption on the error term holds. Hence, we will analyze the problem using a semi-parametric approach, more specifically we will use the Ichimura (1993) estimation technique for single index models. Semi-parametric least squares (SLS) estimation will allow us to test for the normality of $\mu_{i t}$ and thus ascertain whether the standard parametric technique is appropriate or not. The test statistic we will use was introduced by Newey (1985) and the specific version we will implement was derived by Schafgans (1998) ${ }^{14}$.

In the table 7 we present probit, random effects probit and SLS estimates of the factors that influence the vote in the open and closed rule respectively. We also present probit and random effect probit estimates for both treatments for elections in round one only in table 8 . Notice that the fairness index does not achieve statistical significance at conventional levels with either the probit or random effects probit. We also conducted estimates including time dummies for every three periods where periods 10 to 12 were the excluded group but none of these coefficients yielded an estimate significant at the $5 \%$ level ${ }^{15}$.

One thing which is striking in these tables are the coefficients reported for our SLS estimates in table 7 and probit estimates in table 8 for the open rule. The data employed for these regressions suggest an almost perfect fit vote $=1\{$ share $+u \geq 0.16\}$, in which case the error term would not be normally distributed since this clearly does not have an infinite support. Thus concerns about fairness clearly does not affect the vote as we realize that all offers which gives a share strictly above 0.16 are accepted, all offers which offer a share strictly bellow 0.16 are rejected ${ }^{16}$.

\footnotetext{
${ }^{14} \mathrm{~A}$ more detailed description of this test statstic and semi parametric least squares may be found in $\mathrm{Appendix} C$ and $\mathrm{Appendix} D$.

${ }^{15}$ We also put in a dummy variuable to capture the ten election session to see if it was significantly different from the other sessions. The results strongly suggest that there are no differences between the sessions of different length. These estimates along with those with the time dummies are available from the authors upon request.

${ }^{16}$ Nonetheless, this is saying that for any combination of parameters, there is no combination for which having a non-zero coefficient on
} 


\begin{tabular}{|c|c|c|c|c|}
\hline & \multicolumn{2}{|c|}{ Closed Rule } & \multicolumn{2}{|c|}{ Open Rule } \\
\hline $\begin{array}{l}\text { Independent } \\
\text { Variable }\end{array}$ & Probit & $\begin{array}{l}\text { Random } \\
\text { Effects Probit }\end{array}$ & Probit & $\begin{array}{l}\text { Random } \\
\text { Effects Probit }\end{array}$ \\
\hline Share & $\begin{array}{l}29.345 \\
(5.393)\end{array}$ & $\begin{array}{l}68.267 \\
(16.916)\end{array}$ & Dropped & $\begin{array}{l}298.267 \\
(* * *)\end{array}$ \\
\hline Fairness Index & $\begin{array}{l}3.842 \\
(5.125)\end{array}$ & $\begin{array}{l}-2.396 \\
(9.732)\end{array}$ & $\begin{array}{l}-21.580 \\
(18.048)\end{array}$ & $\begin{array}{l}-22.035 \\
(21.909)\end{array}$ \\
\hline Constant & $\begin{array}{l}-4.559 \\
(1.022)\end{array}$ & $\begin{array}{l}-10.808 \\
(2.748)\end{array}$ & $\begin{array}{l}1.127 \\
(0.554)\end{array}$ & $\begin{array}{l}-46.454 \\
(1.037)\end{array}$ \\
\hline Sample Size & $\mathrm{N}=220$ & $\mathrm{~N}=220$ & $\mathrm{~N}=15$ & $\mathrm{~N}=164$ \\
\hline Log Likelihood & -44.337 & $\begin{array}{l}-29.731 \\
\end{array}$ & -7.919 & -7.900 \\
\hline
\end{tabular}

Table 8: Econometric Estimates of the Voting Equation for Round 1 Only

As there is not infinite support for the error term our model is unidentified and we can not test for normality of the error term.

There is an additional remark as it relates to the reliability of the results presented in the table 7 and table 8 . The standard errors for the probit estimates are probably underestimated since the true errors are correlated across elections for the same subject. This problem can be simply corrected with a robust variance matrix calculation. We conducted a Hausman (1978) specification test between the probit and more efficient random effects probit. The results of the test suggest that the random effects probit is preferred in the closed rule both treatments ${ }^{\mathbf{1 7}}$. It should be noted that these results would be weakened if the standard errors were corrected for the probit ${ }^{18}$. Using the Schafgans test, we do not reject the null hypothesis of the nor mality of the error term with data from the closed rule sessions ${ }^{19}$.

The behavior that individual payoff rather than fairness determines the vote also appears in the runoff elections. We modify the regression equation as follows

$$
\text { vote }_{i t}=\beta_{0}+\beta_{1}\left(s_{i t}^{a}-s_{i t}^{o}\right)+\beta_{2}\left(F I_{i t}^{a}-F I_{i t}^{o}\right)+\mu_{i t} ; \quad \mu_{i t} \sim N\left(0, \sigma^{2}\right)
$$

where vote now equals one if the subject voted in favor of the amendment and zero if in favor of the original proposal. The explanatory variables are the difference in the share and FI between the amendment and original proposal. Probit and random effect probit estimates of this equation are shown in table 9 for subjects whose proposals are not being balloted against. Notice again FI does not achieve statistical significance. The results of the Hausman test suggest that the probit is the preferred specification for the runoff elections ${ }^{20}$. A close examination of the data reveals that in the two circumstances that the individual chose an allocation which made him worse off occurred beyond the third round and seem to indicate a desire to end the election.

fairness gives a better fit.

${ }^{17}$ Hausman statistic for the closed rule is 5.785 and is $\mathbf{0 . 5 1 9}$ for the open rule. The results do not change in the case of the closed rule using the data only for round one as the Hausman statistic increases to 6.024 . We can not compute the Hausman statistic for the open rule in this case as the model is unidentified. Since the error term does not have infinite support we would not reccomend the use of either method.

${ }^{18}$ The corrected standard errors would yield a larger difference between the variance covarince matrix of the estimators thereby decreasing the Hausman test statistic. Note a Information Matrix test may also be employed as a specification test. This test treats the two models as part of a larger model and computes the difference between the maximized value of the likelihood functions. Twice the difference will be distributed $\chi^{2}(1)$.

${ }^{19}$ More specifically, our test statistics was 4.080 , which can be rejected only at levels lower than $77 \%$.

${ }^{20}$ The Hausman test statistic is 0.189 . 


\begin{tabular}{|l|l|l|}
\hline Independent Variable & Probit & $\begin{array}{l}\text { Random } \\
\text { Effects Probit }\end{array}$ \\
\hline Difference in Share & -9.613 & -10.887 \\
$s_{i t}^{a}-s_{i t}^{o}$ & $(2.000)$ & $(3.586)$ \\
\hline Difference in Fairness Index & -0.603 & -0.294 \\
$F I_{i t}^{a}-F I_{i t}^{o}$ & $(3.199)$ & $(3.569)$ \\
\hline Constant & 0.286 & 0.338 \\
& $(0.208)$ & $(0.279)$ \\
\hline Log Likelihood & -29.585 & -29.448 \\
\hline
\end{tabular}

Table 9: Runoff Results

It is clear from our estimates that concerns about fairness do not affect individual decisions whether to accept a proposal in either treatment ${ }^{21}$. These results are at odd with the majority of the literature on bargaining experiments. In the next section, we discuss why our results differ from the work of others and present our concluding thoughts.

\section{Conclusions}

In this paper, we examine the performance of non cooperative legislatures theory in the laboratory. We design an experiment where only the procedural rule differs across sessions. We found that over time the different procedures led to different budget outcomes in terms of size and allocation of benefit. We found that divisions in the closed rule became more uneven with the proposer seeking a larger share of the budget than the other members of the coalition. However, the proposer never proposed herself a share as large as that predicted by theory. The evolution of strategies in the closed rule leads to less even distribution as subjects learn that playing the DZ strategy will lead to acceptance.

Divisions in the open rule offered positive amounts of money to more subjects and were accepted more rapidly than predicted by theory. In the open rule sessions subjects quickly learn that amendments are costly and propose distributions which are likely to be seconded. These distributions either take the form of an even split among the subjects or follow the SZ strategy.

Our econometric estimates clearly demonstrate that concerns about fairness do not affect individual decisions whether to accept a proposal in either treatment. These results are at odd with the majority of the literature on bargaining experiments such as Ochs and Roth (1989). They report results from a series of sequential two person alternating offer bargaining experiments. They suggest that the observed behavior can not be explained solely by their own monetary return. Specifically, considerations of fairness enter the utility function. These differences may be the result of having more than two subjects split the pie (see Kagel and Wolfe (1999) for a three person bargaining game).

To summarize we found that different procedures in a sequential model of multilateral bargaining with majority rule experiment led to different outcomes in terms of size and allocation of benefit. These differences across treatments are magnified over time as subjects attempt to propose divisions that would be passed instantaneously while at the same time trying to increase their own share. Divisions are more equitable and the power of the proposer is weakened under the open rule.

\footnotetext{
${ }^{21}$ They clearly do not affect decisions in a statistically significant manner and also if you compare the size of the coefficient on fairness to that of share they are not economically significant either.
} 


\section{A Instructions for the Closed Rule}

This is an experiment in the economics of decision making. Funding for this research has been provided by the University of Pittsburgh. The instructions are simple, and if you follow them carefully and make good decisions you may earn a CONSIDERABLE AMOUNT OF MONEY which will be PAID TO YOU IN CASH at the end of the experiment.

1. In this experiment you will act as voters that distribute funds between yourself and others in a series of elections. In each election you must decide how to split a sum of money. Proposals will be voted up or down (accept or reject) by majority rule. That is, once 3 out of 5 voters approve a proposal, it passes.

2. In each election you will have to decide how to divide $\$ 25.00$ among the five voters. Each voter will write the division that he or she proposes on a proposal form. Allocations to each subject must be between $\$ 0.00$ and $\$ 25.00$. Allocations must add up to $\$ 25.00$.

3. After the proposal forms have been collected, the experimenter will roll a die to determine which proposal will be voted upon. The subject number of the individual whose proposal will be voted upon and his or her proposal will be posted on the blackboard. Once this proposal has been posted each of you have to decide whether to accept or reject the division currently proposed. If 3 out of 5 of the voters accept the proposal than it passes.

4. If the proposal is defeated (gets less than 3 votes), there will be a call for new proposals and the process repeats itself in a new round of the election. However, the amount of money to be divided will be reduced by $20 \%$ of the amount of money in the preceding round of the election. Thus, if the first proposal is rejected, new proposals for this election will involve splitting $\$ 20$ among the 5 voters. And if this new proposal is rejected in round 2 , then in round 3 you will be splitting $\$ 16$.

5. As before, the experimenter will collect the proposal forms and we would have an election with ALL of the voters participating. Once a simple majority approves the proposal the election ends and each voter writes down their payoff on their record sheet.

6. To summarize, the steps in the election process will work as follows:

Step 1: Everyone submits a proposal to split $\$ 25$

Step 2: One proposal, selected at random, has the floor.

Step 3: An election is held.

Step 4: If three (or more) out of five voting for it, it passes and the election is over. If the proposal is rejected, go back to step 1 only the amount of money available shrinks by $20 \%$. This process repeats itself until a proposal is voted in.

7. At the conclusion of the experiment four elections will be selected at random for payment. A roll of a fifteensided die done by four voters will do this. All subjects will be paid in CASH the sum of the outcomes of the four rounds at the end of the experiment. In addition you will receive $\$ 5.00$, as promised, for participating in the study.

8. No one may allocate less than $\$ 0.00$ to any voter. Allocations must be rounded to the nearest penny to be accepted.

9. Each one of you has been assigned a subject ID, which is taped to your desk. Your ID begins with a letter. In each election, you will be randomly assigned a subject number $(1,2,3,4$, or 5$)$. This is strictly private information and is not to be revealed to anyone else. Since subject numbers will be randomly assigned prior to the start of each election all the voters are likely to have their subject numbers vary between elections.

10. You are not to reveal your (potential) earnings, nor are you to speak to any other subject while the experiment is in progress. This is important to the validity of the study and will not be tolerated.

11. We will have one practice election to familiarize you with the procedures and accounting rules. This will be followed by 15 elections played for cash.

12. Review. Let's summarize the main points:

- The experiment will consist of fifteen elections. There may be several rounds for each election. 
- You will be randomly assigned a subject number for each election.

- At the start of each election you will all propose a split of $\$ 25.00$ between the five of you.

- Proposals to each voter must be greater than or equal to $\$ 0.00$

- A proposal to be voted upon will be randomly selected in each round of the election.

- If a simple majority accepts the proposal the election ends.

- If a simple majority rejects the proposal then every voter will be eligible to make a proposal in subsequent rounds of a given election.

- The amount of money to be divided shrinks by $20 \%$ following each rejection of a proposal in a given election. Are there any questions? 


\section{B Instructions for the Open Rule}

This is an experiment in the economics of decision making. Funding for this research has been provided by the University of Pittsburgh. The instructions are simple, and if you follow them carefully and make good decisions you may earn a CONSIDERABLE AMOUNT OF MONEY which will be PAID TO YOU IN CASH at the end of the experiment.

1. In this experiment you will act as voters that distribute funds between yourself and others in a series of elections. In each election you must decide how to split a sum of money. Proposals will be voted up or down (accept or reject) by majority rule. That is, once 3 out of 5 voters approve a proposal, it passes.

2. In each election you will have to decide how to divide $\$ 25.00$ among the five voters. Each voter will write the division that he or she proposes on a proposal form. Allocations to each subject must be between $\$ 0.00$ and $\$ 25.00$. Allocations must add up to $\$ 25.00$.

3. After the proposal forms have been collected, the experimenter will roll a die to determine which proposal will have the floor. The subject number of the individual whose proposal is on the floor and his or her proposal will be posted on the blackboard.

4. After this proposal has been posted, one of the four remaining voters, will have an opportunity to second this proposal or to offer an amendment to the proposal offering an alternative distribution of the $\$ 25$. Which of the four voters have the opportunity to second or amend the proposal will be determined at random, with each of the four voters having an equally likely chance of being chosen.

5. If the proposal in its current form is seconded, it will then be voted on by the group as a whole. If 3 of 5 vote for it, it then passes. If the proposal is defeated (gets less than 3 votes), there will be a call for new proposals and the process repeats itself in a new round of the election.

6. If the proposal is amended, a run-off election will be held between the original proposal and the amendment. Whoever wins the run-off (gets 3 or more of the 5 votes) will be the standing proposal in the next round of the election.

7. After a run-off is held, the process repeats itself - there will be an opportunity to second the standing proposal (in which case it will be voted up or down) or to amend the standing proposal (in which case there will be another run-off between the standing proposal and the new amended proposal).

8. There are costs to making an amendment or to voting down a proposal that has been seconded. The cost is that the amount of money to be distributed across voters shrinks by $20 \%$. This will work as follows: - If the first proposal has been seconded but voted down (is rejected), new proposals will involve splitting $\$ 20$ - Following a run-off election, the winning (standing) proposal will have all values reduced by $20 \%$ before that proposal has a chance to be seconded or subject to further amendment. To summarize, the steps in the election process will work as follows:

Step 1: Everyone submits a proposal to split $\$ 25$

Step 2: One proposal, selected at random, has the floor.

Step 3: One voter, selected at random, will have a chance to either amend or to second the proposal in step 2. (You cannot second or amend your own proposal.)

Step 4a: If the proposal is seconded, it is voted on. Three (or more) out of five voting for it, it passes and the election is over. If the proposal is rejected, go back to step 1 only the amount of money available shrinks by $20 \%$. OR

Step 4b: If the proposal is amended there is a run-off election between the original proposal and the amendment. Whoever wins the run-off replaces the proposal in step 2 with all values reduced by $20 \%$.

This process repeats itself until a proposal is voted in.

9. At the conclusion of the experiment four elections will be selected at random for payment. A roll of a fifteensided die done by four voters will do this. All subjects will be paid in CASH the sum of the outcomes of the three 
rounds at the end of the experiment. In addition you will receive $\$ 5.00$, as promised, for participating in the study.

10. No one may allocate less than $\$ 0.00$ to any voter. Allocations must be rounded to the nearest penny to be accepted.

11. Each one of you has been assigned a subject ID, which is taped to your desk. Your ID begins with a letter. In each election, you will be randomly assigned a subject number $(1,2,3,4$, or 5$)$. This is strictly private information and is not to be revealed to anyone else. Since subject numbers will be randomly assigned prior to the start of each election all the voters are likely to have their subject numbers vary between elections.

12. You are not to reveal your (potential) earnings, nor are you to speak to any other subject while the experiment is in progress. This is important to the validity of the study and will not be tolerated.

13. We will have two practice elections to familiarize you with the procedures and accounting rules. This will be followed by 15 elections played for cash.

14. Review. Let's summarize the main points.

- The experiment will consist of fifteen elections. There may be several rounds for each election

- You will be randomly assigned a subject number for each election.

- At the start of each election you will all propose a split of $\$ 25.00$ between the five of you.

- Proposals to each voter must be greater than or equal to $\$ 0.00$

- The initial proposal to be voted on will be randomly selected in each round of the election.

- An individual will then be randomly selected to second or amend this proposal.

- If the proposal is seconded an election will be held.

- If the proposal is amended a runoff election between the original proposal and the amendment will take place. A simple majority will determine the standing proposal in the next round of the election. The standing proposal must be seconded or amended.

- Once a proposal has been seconded it will be voted upon by every voter.

- If a simple majority accepts the proposal the election ends.

- If a simple majority rejects the proposal all voters are eligible to make a proposal in subsequent rounds of a given election.

- The amount of money to be divided shrinks by $20 \%$ following each election.

Are there any questions? 


\section{SLS Estimation}

The single-index model is, in our case, defined by

$$
D_{i t}=\phi\left(x_{i t}^{\prime} \theta_{0}\right)+u_{i t} \forall i, t
$$

where

$$
E\left(u_{i t} \mid x_{i t}\right)=0
$$

The Ichimura (1993) SLS estimator is given by

$$
\hat{\theta}=\underset{\substack{\theta \in \Theta \\ \theta^{\prime} \theta=1}}{\arg \min }\left\{\frac{1}{n t} \sum_{i=1}^{n} \sum_{t=1}^{T}\left[D_{i t}-\hat{E}\left(D_{i t} \mid x_{i t}^{\prime} \theta\right)\right]^{2} \hat{I}_{i t}\right\}
$$

where $\hat{I}_{i t}$ is a mechanism (trimming function) to make certain that for any $x_{i t}$ and any $\theta, \hat{E}\left(D_{i t} \mid x_{i t}^{\prime} \theta\right)$ is bounded away from zero, and the local linear regression estimator of the conditional mean of the outcome variable, at a given point $i=0, t=0$, is given by

$$
\widehat{E}\left(D_{00} \mid x_{00}^{\prime} \theta\right)=\frac{\sum_{i=1}^{n} \sum_{t=1}^{T} D_{i t} K\left(\frac{\left(x_{i t}-x_{00}\right)^{\prime} \theta}{h}\right)}{\sum_{i=1}^{n} \sum_{t=1}^{T} K\left(\frac{\left(x_{i t}-x_{00}\right)^{\prime} \theta}{h}\right)}
$$

and $K(\cdot)$ denotes some kernel.

The trimming function $\hat{I}_{i t}$ ensures that the conditional mean of the dependent variable has positive density at any point and at any value of the parameters. For our purpose, we have estimated the density at various points using an Epanechnikov kernel. The bandwidth was computed using the optimal bandwidth for the Epanechnikov kernel under the assumption of a normal distribution. If normality does not hold, this as for effect to oversmooth (?). ${ }^{22}$ We did a grid search over the unit circle, and for every value of the parameter, we trimmed the three percent of the data with the lowest density.

For this part of the estimation we will employ the biweight kernel and determine the bandwidth by cross-validation. That is the bandwidth is chosen to satisfy

$$
\hat{h}_{c v}=\underset{h}{\arg \min } \frac{1}{n T} \sum_{i=1}^{n} \sum_{t=1}^{T}\left[D_{i t}-\hat{E}_{h}^{-i t}\left(D_{i t} \mid x_{i t}^{\prime} \theta\right)\right]^{2} \hat{I}_{i t}
$$

such that $h$ includes $k+1$ observations around each it

where the superscript -it means excluding point it. When estimating the parameters, a different bandwidth is computed for every $\theta$ attempted by the optimizer. Also it is worth mentioning that we have used the probit estimates as the starting values for optimization.

\footnotetext{
${ }^{22}$ This approach for trimming was suggested to us by Professor Hidehiko Ichimura.
} 


\section{Normality Test}

Denote the parameters of the probit, excluding the variance and the constant, $\theta_{p}$ and the parameters of the Ichimura estimator, excluding the constant, $\theta_{i},$. Then we can test for the normality of the error term using the test statistic

$$
i^{\prime} \widehat{m}\left(\left(I-\widehat{G} P^{\prime} P\left(\widehat{G}^{\prime} \widehat{G}\right)^{-1} \widehat{G}\right)\left(\left(I-\widehat{G} P^{\prime} P\left(\widehat{G}^{\prime} \widehat{G}\right)^{-1} \widehat{G}\right)^{\prime}\right)\right)^{-1} i \widehat{m}^{\prime}
$$

where $i$ is a vector of ones, $\widehat{m}$ is given by the moment condition of the Ichimura estimator $\sum_{i=1}^{n} \sum_{t=1}^{T} E_{\theta_{0}}\left(m_{i t}\left(D_{i t}, \theta_{0}\right)\right) \equiv$ $\sum_{i=1}^{n} \sum_{t=1}^{T} E_{\theta_{0}}\left[\left(D_{i t}-\hat{E}_{h}^{-i t}\left(D_{i t} \mid x_{i t}^{\prime} \theta\right)\right) \frac{\partial E\left(y_{i t} \mid x_{i t}^{\prime} \theta_{0}\right)}{\partial \theta} \hat{I}_{i t}\right]=0, I$ is the identity matrix, $\widehat{G}$ is the matrix of estimates of $\frac{\partial \log L_{i t}}{\partial \beta}$ where $\beta$ is the entire set of probit parameters, and $P$ the matrix $\left[\begin{array}{cccccc}0 & 0 & 1 & 0 & \cdots & 0 \\ 0 & 0 & 0 & 1 & & 0 \\ \vdots & \vdots & \ddots & \\ \vdots & 0 & 0 & 0 & 1\end{array}\right]$ with rows equal to the number of probit parameters minus two and the number of columns equal to the number of probit parameters. ${ }^{23}$ This statistic has a chi-squared distribution with degrees of freedom equal to the number of probit parameters minus two.

\footnotetext{
${ }^{23}$ For a more detailed exposition of this particular statistics see Schafgans 1998 , and for a more general derivation Newey 1985.
} 
??????? 